\title{
AVALIAÇÃO DA INFLUÊNCIA DA TEMPERATURA E DO TRATAMENTO ENZIMÁTICO NO COMPORTAMENTO REOLÓGICO DO SUCO DE ABACAXI PÉROLA (Ananas comosus L. Merr.) ${ }^{1}$
}

\author{
ADRIANO CESAR CALANDRINI BRAGA², ANTONIO MANOEL DA CRUZ RODRIGUES ${ }^{3}$, \\ LUIZA HELENA MELLER DA SILVA ${ }^{3}$, LÍCIA AMAZONAS DE ARAÚJO ${ }^{4}$
}

RESUMO-O objetivo deste trabalho foi determinar o comportamento reológico do suco de abacaxi- pérola natural e tratado com enzimas pectinolíticas. As condições de tratamento enzimático foram otimizadas através de um planejamento experimental do tipo fatorial completo $2^{\mathrm{k}}$, com três repetições do ponto central. Na avaliação do comportamento reológico foram utilizadas duas amostras submetidas a peneiramento $(\mathrm{Ne} D)$, analisadas em quatro diferentes temperaturas $\left(10 ; 25 ; 50\right.$ e $\left.65^{\circ} \mathrm{C}\right)$. As análises reológicas foram realizadas utilizando um viscosímetro de cilindros concêntricos Brookfield e os dados experimentais foram ajustados ao modelo de Mizrahi-Berk. A relação entre temperatura e viscosidade aparente foi descrita por uma equação tipo Arrhenius. A otimização da atividade enzimática indicou, através da análise de variância e da metodologia de superfície de resposta, que as variáveis temperatura e tempo de tratamento exerceram efeito estatisticamente significativo $(p<0,05)$ sobre a concentração de pectina presente na amostra. O modelo utilizado mostrou-se adequado para descrever o comportamento reológico dos sucos de acordo com os parâmetros $\mathrm{R}^{2}, \chi^{2}$ e $\mathrm{B}_{\mathrm{f}}$. Os baixos valores obtidos para o índice de comportamento indicaram um comportamento pseudoplástico $(\mathrm{n}<1)$. A temperatura exerceu influência sobre a tensão de cisalhamento e a viscosidade aparente dos sucos analisados, sendo os menores valores observados nas amostras analisadas a $65^{\circ} \mathrm{C}$. A equação tipo Arrhenius descreveu de modo satisfatório o efeito da temperatura sobre a viscosidade aparente. Os valores da energia de ativação $\left(\mathrm{E}_{\mathrm{at}}\right)$ foram de 4,54 Kcal.g. $\mathrm{mol}^{-1}$ e 4,89 Kcal.g.mol ${ }^{-1}$, respectivamente, para as amostras do suco de abacaxi natural e despectinizado, aumentando com o tratamento enzimático. A atividade enzimática proporcionou uma redução nos valores dos parâmetros de comportamento reológico das amostras, bem como na viscosidade aparente, em todas as temperaturas utilizadas, sendo o maior percentual de redução observado a $65^{\circ} \mathrm{C}(41,66 \%)$.

Termos para indexação: Sucos de fruta, viscosidade aparente, equação de Arrhenius, despectinização.

\section{EVALUATION OF INFLUENCE FROM TEMPERATURE AND ENZYMATIC TREATMENT IN THE RHEOLOGICAL BEHAVIOR OF PINEAPPLE (Ananas comosus L. Merr.) JUICE}

\begin{abstract}
The objective this study was determinate the rheological behavior of pineapple juice natural and treated with pectinolytic enzymes. Tests for optimization of enzyme activity used in treatment were realized using a complete factorial planning $2^{\mathrm{k}}$, with three repetitions of center point and two independent variables (temperature and time of treatment). In evaluation of rheological behavior of pineapple juice, were utilized two samples submitted to sieving $(\mathrm{N}$ and $\mathrm{D})$, analyzed in four different temperatures $\left(10,25,50 \mathrm{e} 65^{\circ} \mathrm{C}\right)$. The rheological analyses were realized using a Brookfield concentric cylinders viscometer and the relationship in the temperature and apparent viscosity was described by an equation type Arrhenius. The experimental data were adjusted by the Mizrahi-Berk model. The optimization tests indicated by ANOVA and response surface methodology that the variables temperature and time of treatment have statistically significant effect $(\mathrm{p}<0,05)$ on concentration of pectin present in the samples. The enzymatic treatment was carried with an enzyme concentration of $150 \mathrm{mg} . \mathrm{L}^{-1}$, temperature at $50{ }^{\circ} \mathrm{C}$ and treatment time of 80 minutes. The model used was adequate to describe the rheological behavior of the juices according to the parameters $\mathrm{R}^{2}, \chi^{2}$ e $\mathrm{B}_{\mathrm{f}}$. The reduced values of the behavior index (0.61-0.83 for natural juice and $0.57-0.72$ for despectinized juice $)$ indicated the pseudoplastic behavior $(\mathrm{n}<1)$. The temperature influenced the yield stress and apparent viscosity of the juices analyzed, where the minors values were observed in samples treated at $65^{\circ} \mathrm{C}, 2.4 \mathrm{mPa} . \mathrm{s}$ and $1.4 \mathrm{mPa} . \mathrm{s}$, respectively, for the natural and despectinized samples. The equation of Arrhenius described satisfactorily the effect of temperature in the apparent viscosity. The activation energy values $\left(\mathrm{E}_{\mathrm{at}}\right)$ was of 4.54 Kcal.g.mol ${ }^{-1}$ and $4.89 \mathrm{Kcal} \mathrm{g} . \mathrm{mol}^{-1}$, respectively, for the natural and despectinized samples of pineapple juice, increasing with enzymatic treatment. The enzymatic treatment decreased the values of rheological behavior parameters for samples of pineapple juice, and the apparent viscosity for all temperatures used, where the largest percentage reduction was observed at $65^{\circ} \mathrm{C}(41.66 \%)$.
\end{abstract}

Index terms: Fruit juice, apparent viscosity, Arrhenius equation, despectinization.

\footnotetext{
${ }^{1}$ (Trabalho 213-12). Recebido em: 05-07-2012. Aceito para publicação em: 28-11-2012.

2Professor. Ass. I - Universidade do Estado do Pará/DETA/CCNT - E-mail: accbraga@uepa.br

${ }^{3}$ Professor Ass. I - Universidade Federal do Pará (UFPA) - Campus Universitário do Guamá - E-mails: amcr@ufpa.br; 1hmeller@ufpa.br

${ }^{4}$ Eng. de Alimentos, Mestre em Ciência e Tecnologia de Alimentos .E-mail: licia.araujo@ifpa.edu.br
} 


\section{INTRODUÇÃO}

O abacaxi é a oitava fruta mais produzida no mundo, sendo a sétima entre as produzidas no Brasil. É uma fruta bastante consumida, tanto in natura, como industrializada, apresentando características que fazem com que o mesmo seja muito utilizado na produção de polpas, compotas, doces cristalizados, geleias, sucos (natural e concentrado), sorvetes, cremes, gelatinas e pudins. A cultivar "pérola" é muito apreciada no mercado interno graças a sua polpa suculenta e saborosa, considerada insuperável para o consumo ao natural, fazendo com que os frutos tenham grande potencial de comercialização internacional, pois também são muito apreciados no Mercosul e na Europa (SOUTO et al., 2004).

A viscosidade aparente de sucos e polpas de frutas é influenciada por inúmeros fatores, como a quantidade de sólidos solúveis e insolúveis, a distribuição do tamanho de partículas, o formato das partículas e as variáveis de processo (temperatura, pressão, etc.). Em função de seu comportamento reológico viscoso, os fluidos podem ser classificados em newtonianos e não newtonianos. Nos fluidos newtonianos, a viscosidade mantém-se constante com a variação da taxa de deformação, sendo influenciada apenas por temperatura e pressão. Já nos fluidos não newtonianos, a viscosidade sofre alteração com a variação dos valores da taxa de deformação, podendo ou não depender do tempo de cisalhamento (FERREIRA et al., 2005).

O comportamento mais comum de fluidos alimentícios não-newtonianos independentes do tempo é do tipo pseudoplástico, quando a viscosidade do material diminui com o aumento da taxa de deformação, porém sem a presença da chamada tensão residual $\left(\tau_{0}\right)$, que é uma tensão finita exigida para iniciar o fluxo, sendo utilizada para estimar a espessura do revestimento de superfícies, avaliar a força necessária para que um fluido saia da embalagem, ou dificultar a sedimentação de partículas suspensas (BHATTACHARYA, 1999).

As pectinas são polímeros lineares essencialmente compostos de unidades de ácido D-galacturônico unidas por ligações do tipo $\alpha-1,4$. As unidades de ácido galacturônico podem ter um grau de metilação importante no $\mathrm{C}_{6}$. A presença de outras unidades de açúcares tais como galactose, arabinose e rhamnose ao longo das cadeias de grupos de ácido galacturônico, tem reforçado a compreensão das propriedades das pectinas. Devido a essas propriedades, as pectinas são responsáveis pela turbidez e o aumento da viscosidade de sucos de frutas (BARROS et al., 2004).

As enzimas pectinolíticas ou pectinases são grupos heterogêneos de enzimas que hidrolisam as substâncias pécticas presentes na maioria dos vegetais. As pectinases são amplamente distribuídas em plantas superiores e micro-organismos. A classificação desse tipo de enzima consiste basicamente em três grupos: as de-esterificadoras (pectinesterases), depolimerases (pectinases: hidrolases e lyases) e protopectinases (ALKORTA et al., 1998).

A definição de modelos reológicos adequados à descrição do escoamento é necessária ao projeto de tubulações, bombas, sistemas de agitação e de mistura, além de auxiliarem no controle de qualidade, desenvolvimento de novos produtos e aceitabilidade dos mesmos por parte do consumidor (SILVA et al., 2005). O efeito da temperatura sobre o comportamento reológico precisa ser conhecido para o entendimento e dimensionamento de operações unitárias tais como tratamento térmico e concentração (FERREIRA et al., 2002).

O objetivo deste trabalho foi avaliar a influência da temperatura e do tratamento com enzimas pectinolíticas sobre o comportamento reológico, em estado estacionário, do suco de abacaxi pérola.

\section{MATERIAL E MÉTODOS}

\section{Matéria-prima}

Os frutos de abacaxi pérola utilizados nos experimentos foram adquiridos na Central de Abastecimento de Belém (CEASA). Após seleção (considerando o grau de maturação) e higienização, os frutos foram descascados e despolpados. A polpa obtida foi acondicionada em embalagens de polietileno com capacidade de $500 \mathrm{~g}$, congelada e armazenada em um freezer à temperatura de $-18^{\circ} \mathrm{C}$ até o momento da análise.

\section{prima}

Caracterização físico-química da matéria-

Foram realizadas análises de umidade, sólidos solúveis, acidez, $\mathrm{pH}$, proteínas, lipídeos, cinzas, fibras, açúcares redutores e totais (em glicose) de acordo com a metodologia da AOAC (Association of Official Analytical Chemistry).

\section{Preparação das amostras}

Para as análises reológicas, a polpa de abacaxi foi previamente descongelada $\left(4^{\circ} \mathrm{C}\right)$ e centrifugada a $3.000 \mathrm{rpm}$, por 15 minutos (centrífuga Logen, modelo: MTD III PLUS). O precipitado obtido nessa operação foi submetido durante 25 minutos a um peneiramento, empregando uma peneira de aço inoxidável ( 32 tyler, com abertura de $340 \mu \mathrm{m}$ ) e um agitador mecânico de peneiras da marca Bertel.

A fração obtida no peneiramento foi, posteriormente, reconstituída ao soro na mesma proporção de sólidos presentes na polpa integral. Esse procedi- 
mento originou dois tipos de amostras, denominadas natural $(\mathrm{N})$ e despectinizada (D - tratadas com enzimas pectinolíticas).

\section{Tratamento enzimático}

Para otimizar as condições de atuação da preparação enzimática comercial Pectinex XXL (Novozymes Latin América Limited), no tratamento enzimático do suco de abacaxi, foram usados diferentes níveis de temperatura e tempo de tratamento, através de um planejamento experimental do tipo fatorial completo $2^{\mathrm{k}}$, com três repetições do ponto central, a fim de determinar a faixa em que houve maior hidrólise das pectinas presentes, sendo os ensaios conduzidos de modo randomizado. Foi usada uma concentração de enzima de $150 \mathrm{mg} . \mathrm{L}^{-1}$, levando em consideração que a atividade das pectinases aumenta até uma temperatura de $55^{\circ} \mathrm{C}$ (GOMES et al., 2006).

Após serem definidas as melhores condições de hidrólise da pectina, o tratamento enzimático foi realizado em tubos de aço inoxidável, fechados, com capacidade de $50 \mathrm{~mL}$, ao abrigo da luz. Para interromper a atividade da enzima, as amostras foram submetidas à temperatura de $85{ }^{\circ} \mathrm{C}$, por 5 minutos.

\section{Determinação da viscosidade aparente}

A viscosidade aparente (Equação 1) das amostras do suco de abacaxi foi calculada de acordo com os parâmetros reológicos do modelo de Mizrahi-Berk, tensão inicial $\left(\mathrm{K}_{0 \mathrm{M}}\right)$, índice de comportamento do fluido $(\mathrm{nM})$ e índice de consistência $\left(\mathrm{K}_{\mathrm{M}}\right)$. Substituindo a equação do modelo de Mizrahi-Berk (Equação 4) na Equação 1, tem-se a Equação 2, que foi utilizada para o cálculo de $\eta_{\text {ap }}$ das amostras analisadas.

$$
\begin{aligned}
\eta_{\text {ap }} & =\tau / \gamma \\
\eta_{\text {ap }} & =\left(\mathrm{K}_{0 \mathrm{M}}+\mathrm{K}_{\mathrm{M}} \times \gamma^{\mathrm{nM}}\right)^{2} / \gamma
\end{aligned}
$$

\section{Comportamento reológico}

Os ensaios reológicos foram realizados mediante o emprego de um viscosímetro de cilindros concêntricos Brookfield, modelo LVDV II, acoplado a um banho termostático Haake B3, utilizando o cilindro interno de especificação DIN S85 e o programa de ajuste Wingather ${ }^{\mathbb{B}}$.

O efeito da temperatura sobre a viscosidade aparente pode ser descrito mediante uma equação análoga à de Arrhenius (Equação 3), que indica uma tendência de diminuição da viscosidade aparente com o aumento da temperatura. De modo geral, quanto maior for a energia de ativação, maior será o efeito da temperatura sobre a viscosidade (SILVA et al., 2005).

$$
\eta_{\mathrm{ap}}=\eta_{0} \times \exp \left(\frac{\mathrm{E}_{\mathrm{at}}}{\mathrm{RT}}\right)
$$

Em que : $\eta_{\mathrm{ap}}=$ viscosidade aparente (Pa.s); $\eta_{0}=$ Constante $(\mathrm{Pa} . \mathrm{s}) ; \mathrm{E}_{\mathrm{at}}=$ Energia de ativação para escoamento viscoso (kcal.g.mol $\left.{ }^{-1}\right) ; \mathrm{R}=$ Constante dos gases $\left(1,987 \times 10^{-3} \mathrm{kcal} . \mathrm{g} \cdot \mathrm{mol}^{-1} \cdot \mathrm{K}^{-1}\right) ; \mathrm{T}=$ Temperatura absoluta (K).

Para cada um dos ensaios, foram utilizados $40 \mathrm{~mL}$ de amostra, analisada em quatro diferentes temperaturas: $10 ; 25 ; 50$ e $65^{\circ} \mathrm{C}$. As velocidades rotacionais do cilindro interno estiveram dentro da faixa de 5 a $160 \mathrm{rpm}$, e a taxa de deformação, entre 6,4 e $206 \mathrm{~s}^{-1}$. Antes de iniciar cada ensaio, foi estabelecido um tempo de 10 minutos para a calibração do equipamento.

O modelo reológico proposto por Mizrahi-Berk (Equação 4) tem-se ajustado à maioria das análises reológicas de polpas, sucos e purês de frutas, já que os autores o desenvolveram baseando-se no modelo de uma suspensão de partículas interagindo entre si em um meio pseudoplástico (PELEGRINE et al., 2000).

$$
\tau^{1 / 2}=\mathrm{K}_{0 \mathrm{M}}+\mathrm{K}_{\mathrm{M}} \mathrm{x}(\dot{\gamma})^{\mathrm{nM}}
$$

Em que : $\tau=$ tensão de cisalhamento $(\mathrm{Pa}) ; \gamma=$ taxa de deformação $\left(\mathrm{s}^{-1}\right) ; \mathrm{K}_{\mathrm{M}}=$ índice de consistência $\left(\mathrm{Pa} . \mathrm{s}^{\mathrm{n}}\right) ; \mathrm{nM}=$ índice de comportamento do fluido (admensional); $\mathrm{K}_{0 \mathrm{M}}=$ raiz quadrada da tensão inicial de cisalhamento.

Os dados de tensão de cisalhamento e a taxa de deformação obtidos experimentalmente foram ajustados ao modelo reológico de MizrahiBerk, através do software Statistica 5.5 (Statsoft - USA), sendo o ajuste avaliado pelos parâmetros estatísticos, coeficiente de correlação $\left(\mathrm{R}^{2}\right)$; quiquadrado $\left(\chi^{2}\right)$, obtido da Equação 5, onde é expressa a diferença entre os valores calculados e os obtidos experimentalmente, e o fator bias ( $\left.\mathrm{B}_{\mathrm{f}}\right)$ (Equação 6). Uma boa relação entre os valores observados e os preditos deve possuir um valor de $\mathrm{B}_{\mathrm{f}}$ igual à unidade.

$$
\begin{aligned}
& \chi^{2}=\sum\left(\mathrm{V}_{\text {Exp }}-\mathrm{V}_{\text {Pred }}\right)^{2} / \mathrm{N}-\mathrm{n} \\
& \mathrm{B}_{\mathrm{f}}=10^{\left[\sum(\mathrm{VExp}-\mathrm{V} \text { Pred })^{2} / \mathrm{N}\right]}
\end{aligned}
$$

Em que : $V_{\text {Exp }}=$ Valores obtidos experimentalmente; $\mathrm{V}_{\text {Pred }}=$ Valores preditos pelo ajuste do modelo; $\mathrm{N}=$ número de observações; $\mathrm{n}=$ número de parâmetros do modelo. 


\section{RESULTADOS E DISCUSSÃO}

\section{Caracterização físico-química da matéria- prima}

Os resultados obtidos na caracterização da polpa de abacaxi são descritos na Tabela 1 .

Verifica-se que, na polpa de abacaxi analisada, destacam-se os elevados teores de açúcares, sendo predominantes os açúcares redutores, que podem favorecer reações de escurecimento não enzimático. A quantidade de fibras foi de $0,85 \%$, e os teores de sólidos solúveis encontrados foram inferiores aos estimados por Pinheiro et al. (2006), para o suco integral de abacaxi (cerca de $13,5^{\circ}$ Brix). O conteúdo de cinzas foi pequeno, aproximadamente $0,3 \%$. O valor de $\mathrm{pH}$ encontrado foi menor que o obtido por Sarzi e Durigan (2002) para amostras de abacaxipérola, que foi de 3,8 .

\section{Tratamento enzimático}

As concentrações de pectina determinadas para cada ensaio utilizado na otimização das condições de tratamento enzimático podem ser observadas na Tabela 2.

A concentração de pectina presente na amostra de abacaxi integral foi de 1.770,4 mgAG.L ${ }^{-1}$. Ao analisar os resultados obtidos, verifica-se que o tratamento que proporcionou a menor concentração de pectina, dentre todos os ensaios realizados, promovendo maior hidrólise na amostra pela atuação da enzima, resultou na redução de 94,03\% em sua concentração.

Os resultados obtidos na análise de variância mostraram que as variáveis temperatura e tempo de tratamento exercem efeito estatisticamente significativo sobre a resposta $(p<0,05)$, nas condições utilizadas. Conforme há um aumento tanto da temperatura quanto do tempo, verifica-se redução na concentração de pectina das amostras analisadas. Todavia, a interação entre os dois parâmetros não exerceu efeito estatisticamente significativo sobre a resposta para $\mathrm{p}<0,05$.

Uma mudança nos níveis das variáveis temperatura e tempo (do menor para o maior nível) causa redução no valor da resposta, sendo este efeito desejável. O efeito significativo da temperatura era esperado, uma vez que esta variável apresenta grande influência sobre a velocidade das reações enzimáticas, havendo o máximo de atividade na faixa de temperatura ótima de atuação da enzima que, no caso das pectinases, é de até $55^{\circ} \mathrm{C}$, variando em função da classificação da enzima (de-esterificadora, depolimerases ou protopectinases). Este fato justifica a influência significativa do maior nível de temperatura utilizado nos ensaios $\left(50^{\circ} \mathrm{C}\right)$, pois o mesmo encontra-se na faixa ótima de atuação da enzima utilizada (JAYANE et al., 2005).

A Figura 1 mostra a superfície de resposta construída a partir dos dados obtidos na otimização do tratamento enzimático. Verifica-se que o menor valor de concentração de pectina obtido foi de $105,5 \mathrm{mgAG} \cdot \mathrm{L}^{-1}$. Na faixa de trabalho utilizada (30$50{ }^{\circ} \mathrm{C}$ e $40-80$ minutos), levando em consideração que uma redução de tempo e temperatura resulta num aumento da concentração de pectina das amostras, obteve-se como condição otimizada de tratamento enzimático a temperatura de $50{ }^{\circ} \mathrm{C}$ e tempo de 80 minutos (ensaio 4), proporcionando a redução de $94,03 \%$ na concentração de pectina da amostra de abacaxi integral analisada.

Barros et al. (2004), ao estudarem o suco de abacaxi, verificaram que, ao realizar o tratamento enzimático variando a concentração de enzima entre 20; 100 e $300 \mathrm{mg} . \mathrm{L}^{-1}$, à temperatura de $40{ }^{\circ} \mathrm{C}$, por 60 minutos, a maior redução da concentração de ácido galacturônico foi obtida com o tratamento que utilizou a menor concentração de enzima, ou seja, $20 \mathrm{mg} . \mathrm{L}^{-1}$, a $40{ }^{\circ} \mathrm{C}$, por 60 minutos.

\section{Comportamento reológico}

Os resultados obtidos pelo ajuste dos dados experimentais das amostras do suco de abacaxi $(\mathrm{Ne}$ D) ao modelo de Mizrahi-Berk indicaram elevados valores de $\mathrm{R}^{2}(>0,98)$ para todas as amostras analisadas, além de baixos valores de $\chi^{2}$ e um fator bias $\left(\mathrm{B}_{\mathrm{f}}\right)$ próximo a um, sendo por isso aceitável para descrever o comportamento reológico das mesmas. As Tabelas 3; 4; 5 e 6 mostram os parâmetros de ajuste do modelo de Mizrahi-Berk para as amostras, nas quatro temperaturas analisadas.

Queiroz et al. (2000) analisaram amostras de suco de abacaxi naturais e despectinizadas, utilizando o modelo de Mizrahi-Berk. Esses autores observaram, em cinco dos seis ajustes, valores de $\mathrm{R}^{2}$ acima de 0,97 e SSR (soma dos quadrados dos resíduos) inferior a 0,01 , configurando a adequação do modelo para caracterizar o comportamento reológico dos materiais utilizados, de modo similar ao observado neste trabalho.

Ao avaliar os valores dos índices de comportamento dos sucos natural e despectinizado (Tabela 7), observa-se que as amostras apresentaram comportamento não newtoniano, sendo classificadas como fluidos pseudoplásticos $(\mathrm{n}<1)$. Da mesma forma, Ferreira et al. (2008) encontraram, para as amostras de polpa de cupuaçu analisadas, valores de índice de comportamento de fluxo (n) inferiores a 1, caracterizando, dessa forma, um comportamento não 
newtoniano.

Este comportamento (pseudoplasticidade) também foi verificado por Pelegrine et al. (2000) e Silva et al. (2005), respectivamente, para as polpas de manga e abacaxi, e suco de acerola.

\section{Efeito da temperatura}

Nas Figuras 2 e 3, observa-se o efeito da temperatura sobre o comportamento reológico das amostras $\mathrm{N}$ e D do suco de abacaxi, através do gráfico da tensão de cisalhamento $(\tau)$, em função da taxa de deformação $(\gamma)$, ajustado pelo modelo de Mizrahi-Berk.

Verifica-se que, para uma taxa de deformação constante, há diminuição dos valores de tensão de cisalhamento com o aumento da temperatura. Este efeito pode ser explicado pelo colapso estrutural da polpa devido à força hidrodinâmica gerada e o aumento do alinhamento das moléculas constituintes (ALPARSLAN ;HAYTA, 2002).

Silva et al. (2005) estudaram o efeito da concentração e da temperatura na reologia do suco de acerola. Esses autores verificaram que a viscosidade aparente, calculada a uma taxa de deformação de $100 \mathrm{~s}^{-1}$, aumenta com o inverso da temperatura. Para as amostras de suco de abacaxi analisadas, os valores de $\eta_{\mathrm{ap}}$, calculados a uma taxa de deformação de $103 \mathrm{~s}^{-1}$, diminuíram com o aumento da temperatura, como pode ser observado na Tabela 8 .

Toralles et al. (2006) analisaram o efeito da temperatura e concentração na reologia de purê homogeneizado de pêssego, verificando forte influência da temperatura na viscosidade aparente, que decresceu com o aumento da temperatura, sendo este comportamento também observado nas amostras do suco de abacaxi analisado.

Segundo Constenla et al. (1989), a redução na viscosidade aparente pode ser atribuída a um aumento nas distâncias intermoleculares que ocorrem em função da expansão térmica causada pelo aumento na temperatura. Hassan e Hobani (1998) acrescentam que a força de cisalhamento, quando associada com a aplicação da temperatura, faz com que as partículas se rearranjem em direções paralelas, e as partículas maiores são quebradas em partículas menores. Essas partículas podem escoar mais facilmente como um resultado da diminuição da interação partícula-partícula, a qual resulta na diminuição da viscosidade.

A relação da viscosidade aparente com a taxa de deformação apresentou comportamento semelhante, ou seja, ocorre uma redução nos valores desse parâmetro com o aumento da taxa de deformação nas amostras analisadas, o que é característico do comportamento de fluidos pseudoplásticos. Ferreira et al.
(2002) encontraram esta mesma tendência estudando a reologia da polpa de goiaba. As Figuras 4 e 5 mostram a relação entre a viscosidade aparente e a taxa de deformação das amostras $\mathrm{N}$ e D, respectivamente.

Constata-se que a viscosidade aparente, a partir da taxa de deformação de $103 \mathrm{~s}^{-1}$, tende a ficar constante para as temperaturas de 10 a $65^{\circ} \mathrm{C}$. Isto pode ser relacionado com a redução do tamanho dos agregados coloidais proveniente do aumento da taxa de deformação.

Uma análise de regressão não linear foi usada na equação de Arrhenius (Equação 3), a fim de determinar os parâmetros da relação entre $\eta_{\text {, }}$ (calculada a uma taxa de deformação de $103 \mathrm{~s}^{-1}$ ) e a temperatura. A equação de Arrhenius tem sido usada com sucesso para predizer a dependência da temperatura de fluidos alimentícios ricos em açúcares e sucos de frutas (KHALIL et al., 1989).

A equação de Arrhenius representou de modo satisfatório o efeito da temperatura na viscosidade aparente das amostras do suco de abacaxi, como pode ser visto na Figura 6.

Os valores da energia de ativação $\left(\mathrm{E}_{\mathrm{at}}\right)$ calculados para as amostras analisadas e a taxa de deformação de $103 \mathrm{~s}^{-1}$ podem ser observados na Tabela 9. Em um sistema, altos valores de $\mathrm{E}_{\mathrm{at}}$ indicam uma mudança mais rápida da viscosidade aparente com a temperatura. Comparando a amostra natural à despectinizada, observa-se que, devido ao maior valor de energia de ativação do material despectinizado, essas amostras têm sua estrutura molecular mais influenciada pela temperatura do que o material natural, ou seja, as amostras despectinizadas têm maior facilidade de escoamento devido à maior energia de ativação, do que as amostras naturais. Esse efeito pode ser justificado pela mudança na estrutura das amostras através do tratamento enzimático realizado, onde ocorreu a hidrólise da fração de pectina presente nas amostras, proporcionando mudanças no comportamento reológico das mesmas, sendo mais influenciadas pela mudança de temperatura.

Do ponto de vista industrial, a diminuição da viscosidade facilita o escoamento da polpa e a troca de calor durante o processamento. Sabe-se que, quanto menor a viscosidade de um fluido, menor é a perda de carga durante o escoamento, o que resulta em menor gasto de energia.

\section{Efeito do tratamento enzimático}

A Figura 7 indica o efeito do tratamento enzimático sobre o comportamento reológico das amostras do suco de abacaxi ajustadas pelo modelo de Mizrahi-Berk.

Verifica-se uma redução nos parâmetros de 
comportamento reológico, em função da atuação das enzimas pectinolíticas, que ocasionaram a hidrólise da pectina presente nas amostras do suco de abacaxi, alterando a estrutura das mesmas pela redução do tamanho das macromoléculas ao longo do tempo de tratamento. A Tabela 10 mostra o percentual de redução da viscosidade aparente dos sucos analisados a uma taxa de deformação de $103 \mathrm{~s}^{-1}$.

É possível verificar que houve redução da viscosidade em todas as temperaturas utilizadas, em função do tratamento enzimático, sendo o maior percentual de redução observado na temperatura de $65{ }^{\circ} \mathrm{C}(41,66 \%)$.

Esses valores estão próximos aos encontrados por Barros et al. (2004), que avaliaram a influência da despectinização na ultrafiltração dos sucos de cereja e abacaxi, e observaram redução na viscosidade de $22,3 \%$ para o suco de cereja e $30 \%$ para o suco de abacaxi, em função da redução no peso molecular das pectinas, celuloses e hemiceluloses com o decorrer do tempo de tratamento. Com 50 minutos de tratamento, $80 \%$ do total de pectina do suco de cereja e $30 \%$ do total de pectina do suco de abacaxi, haviam sido despolimerizados, comprovando a eficiência da utilização das enzimas para a hidrólise da pectina.
Sá et al. (2003) analisaram a concentração de suco de abacaxi através dos processos com membranas e verificaram que o tratamento enzimático introduzido ao processamento, com o objetivo de melhorar o desempenho do processo de filtração, reduziu significativamente a viscosidade do suco hidrolisado, em relação ao suco integral, em cerca de $22 \%$, sendo este valor bem próximo ao encontrado para o suco de abacaxi analisado neste trabalho.

Queiroz et al. (2000) verificaram que, com a despectinização, a eliminação total dos sólidos insolúveis suspensos com a centrifugação reduziu a viscosidade aparente da fração centrifugada para menos de 1/19 do valor da viscosidade aparente da polpa integral, a uma taxa de deformação de $300 \mathrm{~s}^{-1}$.

Vaillant et al. (2001) estudaram o processo de clarificação de sucos e polpas de frutas, visando a obter um produto transparente e homogêneo. $\mathrm{O}$ uso de enzimas reduziu a viscosidade do suco, como visto para o suco de abacaxi. Esse resultado facilitou a operação de filtração. Além disso, a baixa viscosidade favoreceu a troca de calor durante os tratamentos térmicos, confirmando a eficiência da utilização das enzimas pectinolíticas na indústria de sucos de frutas.

TABELA 1- Composição físico-química da polpa de abacaxi.

\begin{tabular}{cc}
\hline Análises & Médias \\
\hline Umidade $(\%)$ & $87,12 \pm 0,09$ \\
Sólidos solúveis ( ${ }^{\circ}$ Brix) & $11,50 \pm 0,02$ \\
Cinzas (\%) & $0,30 \pm 0,02$ \\
Lipídeos (\%) & $0,10 \pm 0,015$ \\
Proteínas (\%) & $0,41 \pm 0,23$ \\
Açúcares redutores (\%) & $7,2 \pm 0,003$ \\
Açúcares não redutores (\%) & $4,09 \pm 0,003$ \\
Fibras solúveis (\%) & $0,25 \pm 0,13$ \\
Fibras insolúveis (\%) & $0,60 \pm 0,04$ \\
Acidez (\% de ácido cítrico) & $0,73 \pm 0,08$ \\
pH & $3,46 \pm 0,03$ \\
\hline
\end{tabular}

TABELA 2- Concentração de pectina dos ensaios da otimização do tratamento enzimático.

\begin{tabular}{cccc}
\hline Ensaios & Temperatura $\left({ }^{\circ} \mathbf{C}\right)$ & Tempo (min) & $\begin{array}{c}\text { Concentração de pectina } \\
\left(\mathbf{m g A G . L ^ { - 1 }}\right)\end{array}$ \\
\hline 1 & 30 & 40 & 710,9 \\
2 & 30 & 80 & 365,5 \\
3 & 50 & 40 & 206,9 \\
4 & 50 & 80 & 105,5 \\
$5(\mathrm{C})$ & 40 & 60 & 272,01 \\
$6(\mathrm{C})$ & 40 & 60 & 215,4 \\
$7(\mathrm{C})$ & 40 & 60 & 274,8 \\
\hline
\end{tabular}


TABELA 3- Parâmetros do modelo de Mizrahi-Berk para as amostras do suco de abacaxi a $10^{\circ} \mathrm{C}$.

\begin{tabular}{ccccccc}
\hline \multirow{2}{*}{ Amostra } & \multicolumn{7}{c}{ Parâmetros } \\
\cline { 2 - 7 } & $\mathrm{K}_{0 \mathrm{M}}$ & $\mathrm{K}_{\mathrm{M}}$ & $\mathrm{nM}$ & $\mathrm{R}^{2}$ & $\chi^{2}$ & $\mathrm{~B}_{\mathrm{f}}$ \\
\hline $\mathrm{N}$ & 0,3718 & 0,0347 & 0,6113 & 0,9978 & 0,0004 & 1,0034 \\
$\mathrm{D}$ & 0,2903 & 0,0171 & 0,7201 & 0,9994 & 0,0001 & 1,0020 \\
\hline
\end{tabular}

TABELA 4- Parâmetros do modelo de Mizrahi-Berk para as amostras do suco de abacaxi a $25^{\circ} \mathrm{C}$.

\begin{tabular}{ccccccc}
\hline \multirow{2}{*}{ Amostra } & \multicolumn{7}{c}{ Parâmetros } \\
\cline { 2 - 7 } & $\mathrm{K}_{0 \mathrm{M}}$ & $\mathrm{K}_{\mathrm{M}}$ & $\mathrm{nM}$ & $\mathrm{R}^{2}$ & $\chi^{2}$ & $\mathrm{~B}_{\mathrm{f}}$ \\
\hline $\mathrm{N}$ & 0,4265 & 0,0078 & 0,8293 & 0,9961 & 0,0003 & 1,0028 \\
$\mathrm{D}$ & 0,1134 & 0,0318 & 0,6184 & 0,9989 & 0,0001 & 1,0009 \\
\hline
\end{tabular}

TABELA 5- Parâmetros do modelo de Mizrahi-Berk para as amostras do suco de abacaxi a $50{ }^{\circ} \mathrm{C}$.

\begin{tabular}{ccccccc}
\hline \multirow{2}{*}{ Amostra } & \multicolumn{7}{c}{ Parâmetros } \\
\cline { 2 - 7 } & $\mathrm{K}_{0 \mathrm{M}}$ & $\mathrm{K}_{\mathrm{M}}$ & $\mathrm{nM}$ & $\mathrm{R}^{2}$ & $\chi^{2}$ & $\mathrm{~B}_{\mathrm{f}}$ \\
\hline $\mathrm{N}$ & 0,3531 & 0,0050 & 0,8319 & 0,9952 & 0,0001 & 0,9958 \\
$\mathrm{D}$ & 0,0978 & 0,0253 & 0,5778 & 0,9910 & 0,0001 & 0,9968 \\
\hline
\end{tabular}

TABELA 6- Parâmetros do modelo de Mizrahi-Berk para as amostras do suco de abacaxi a $65{ }^{\circ} \mathrm{C}$.

\begin{tabular}{ccccccc}
\hline \multirow{2}{*}{ Amostra } & \multicolumn{7}{c}{ Parâmetros } \\
\cline { 2 - 7 } & $\mathrm{K}_{\mathrm{OM}}$ & $\mathrm{K}_{\mathrm{M}}$ & $\mathrm{nM}$ & $\mathrm{R}^{2}$ & $\chi^{2}$ & $\mathrm{~B}_{\mathrm{f}}$ \\
\hline $\mathrm{N}$ & 0,2551 & 0,0060 & 0,8074 & 0,9870 & 0,0002 & 0,9926 \\
$\mathrm{D}$ & 0,0282 & 0,0161 & 0,6740 & 0,9828 & 0,0002 & 0,9869 \\
\hline
\end{tabular}

TABELA 7 - Valores dos índices de comportamento calculados nas quatro temperaturas utilizadas.

\begin{tabular}{ccccc}
\hline \multirow{2}{*}{ Amostra } & \multicolumn{4}{c}{ n (índice de comportamento) } \\
\cline { 2 - 5 } & $10{ }^{\circ} \mathrm{C}$ & $25{ }^{\circ} \mathrm{C}$ & $50{ }^{\circ} \mathrm{C}$ & $65^{\circ} \mathrm{C}$ \\
\hline $\mathrm{N}$ & 0,6113 & 0,8293 & 0,8319 & 0,8074 \\
$\mathrm{D}$ & 0,7201 & 0,6184 & 0,5778 & 0,6740 \\
\hline
\end{tabular}

TABELA 8- Influência da temperatura sobre a viscosidade aparente das amostras do suco de abacaxi.

\begin{tabular}{ccccc}
\hline \multirow{2}{*}{$\eta_{\text {ap }}$ (mPa.s) } & \multicolumn{4}{c}{ Temperatura $\left({ }^{\circ} \mathbf{C}\right)$} \\
\cline { 2 - 5 } & 10 & 25 & 50 & 65 \\
\hline $\mathrm{N}$ & 8,9 & 6,0 & 3,2 & 2,4 \\
$\mathrm{D}$ & 5,7 & 4,3 & 2,1 & 1,4 \\
\hline
\end{tabular}

TABELA 9-Valores da energia de ativação para as amostras analisadas.

\begin{tabular}{ccc}
\hline & \multicolumn{2}{c}{ Amostras } \\
\hline & $\mathbf{N}$ & $\mathbf{D}$ \\
\cline { 2 - 3 } $\mathbf{E}_{\text {at }}\left(\right.$ Kcal.g.mol $\left.^{-1}\right)$ & 4,54 & 4,89 \\
\hline
\end{tabular}

TABELA 10- Percentual de redução da viscosidade das amostras do suco de abacaxi a uma taxa de deformação de $103 \mathrm{~s}^{-1}$.

\begin{tabular}{cccc}
\hline Temperatura $\left({ }^{\circ} \mathbf{C}\right)$ & $\eta_{\mathbf{N}}$ (mPa.s) & $\eta_{\mathbf{D}}$ (mPa.s) & \% redução \\
\hline 10 & 8,9 & 5,7 & 35,95 \\
25 & 6,0 & 4,3 & 28,33 \\
50 & 3,2 & 2,1 & 34,37 \\
65 & 2,4 & 1,4 & 41,66 \\
\hline
\end{tabular}




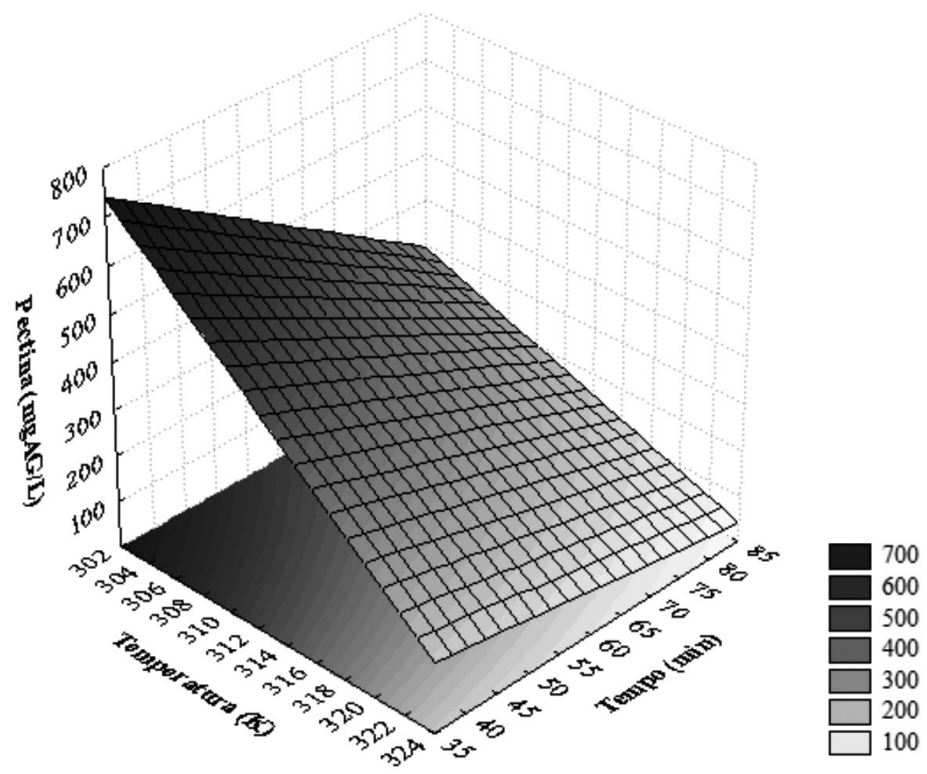

FIGURA 1- Superfície de resposta relativa à concentração de pectina nas condições utilizadas.

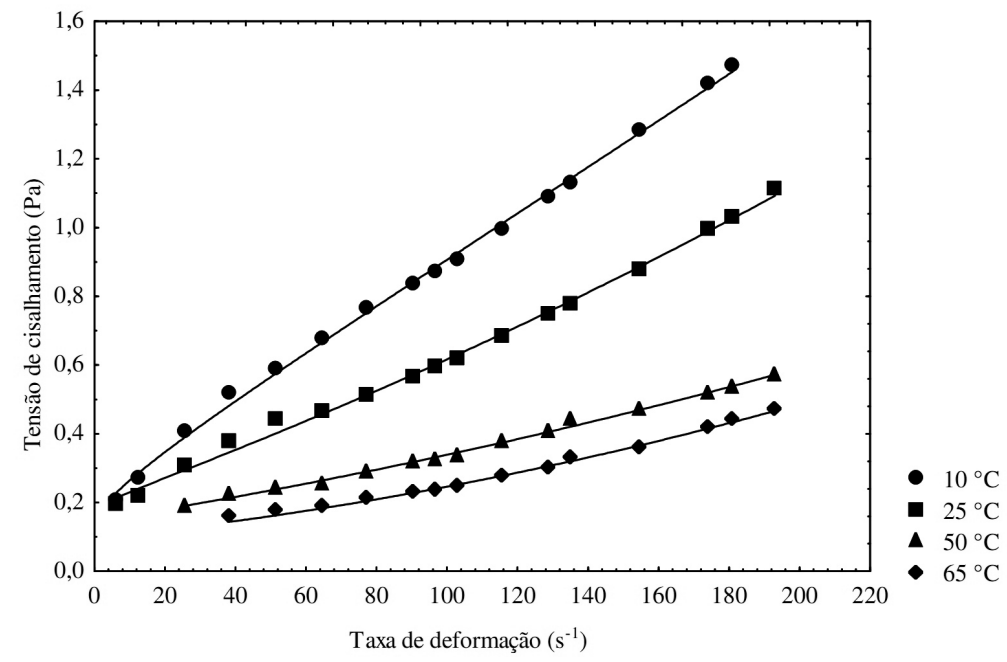

FIGURA 2 - Relação entre tensão de cisalhamento e taxa de deformação da amostra $\mathrm{N}$ do suco de abacaxi ajustada pelo modelo de Mizrahi-Berk. 


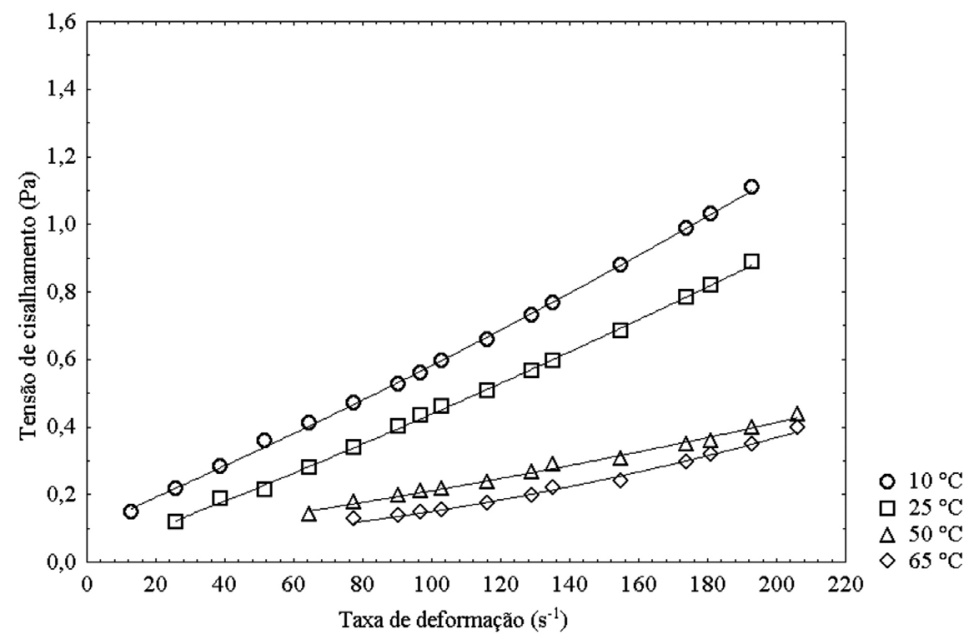

FIGURA 3- Relação entre tensão de cisalhamento e taxa de deformação da amostra D do suco de abacaxi ajustada pelo modelo de Mizrahi-Berk.

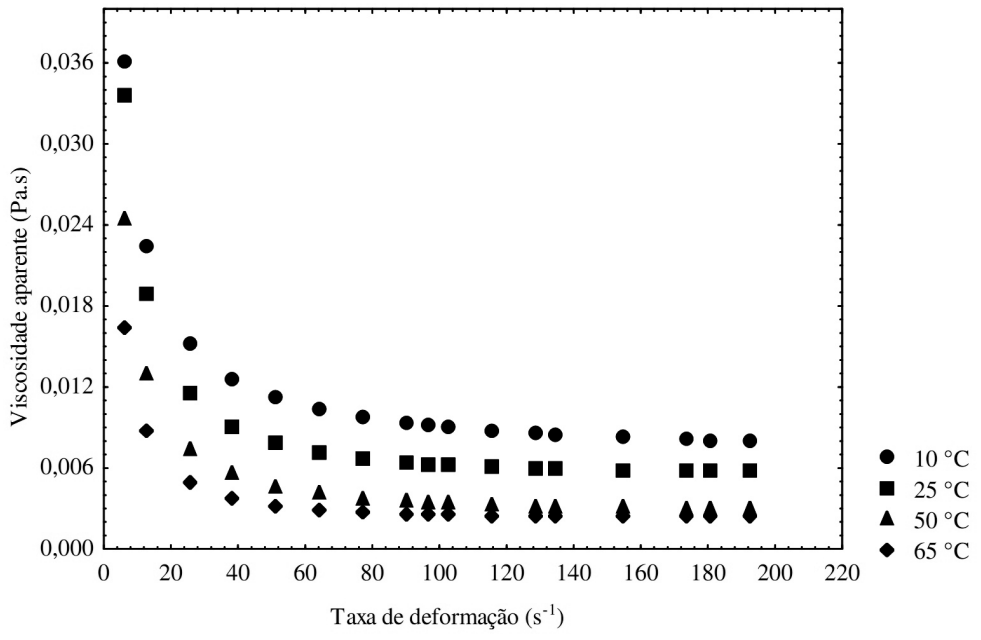

FIGURA 4 - Relação entre viscosidade aparente e taxa de deformação para a amostra N.

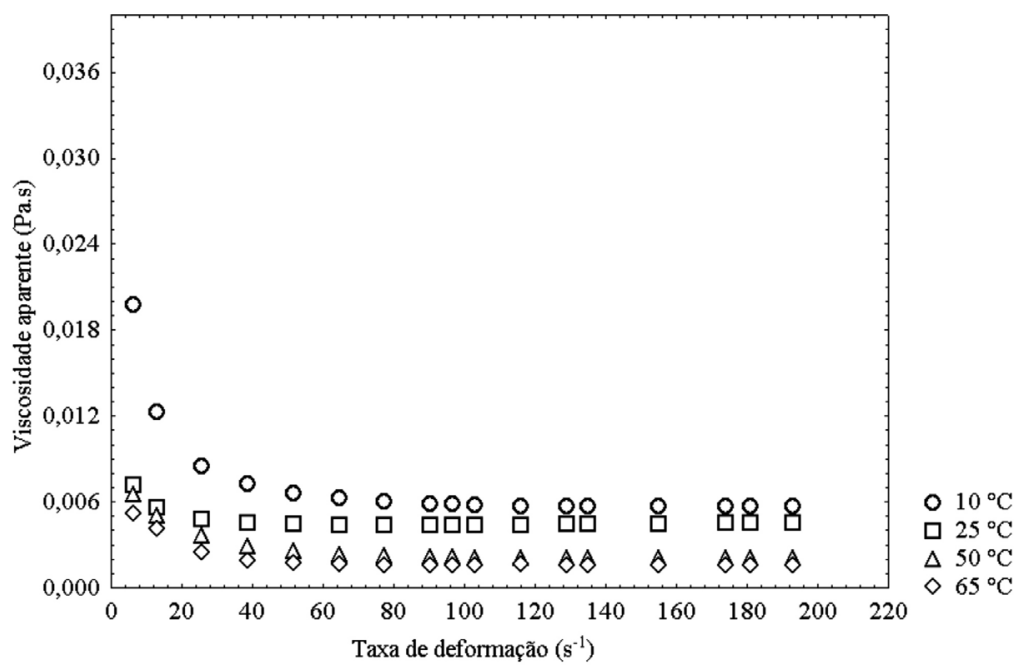

FIGURA 5 - Relação entre viscosidade aparente e taxa de deformação para a amostra D. 


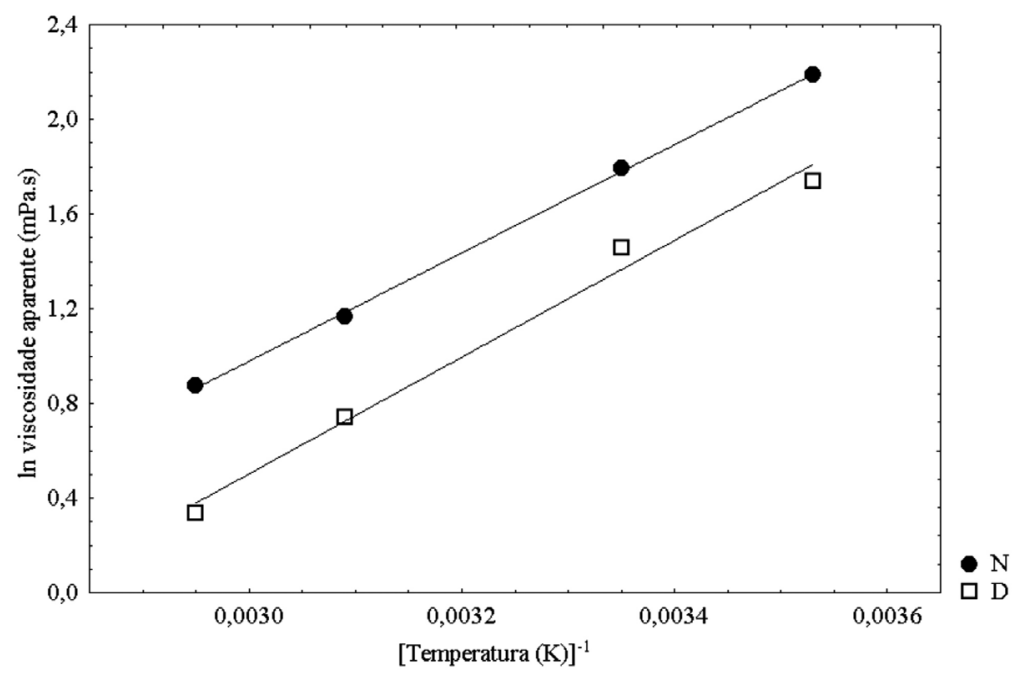

FIGURA 6 - Efeito da temperatura sobre a viscosidade aparente das amostras do suco de abacaxi ajustado pela equação de Arrhenius.

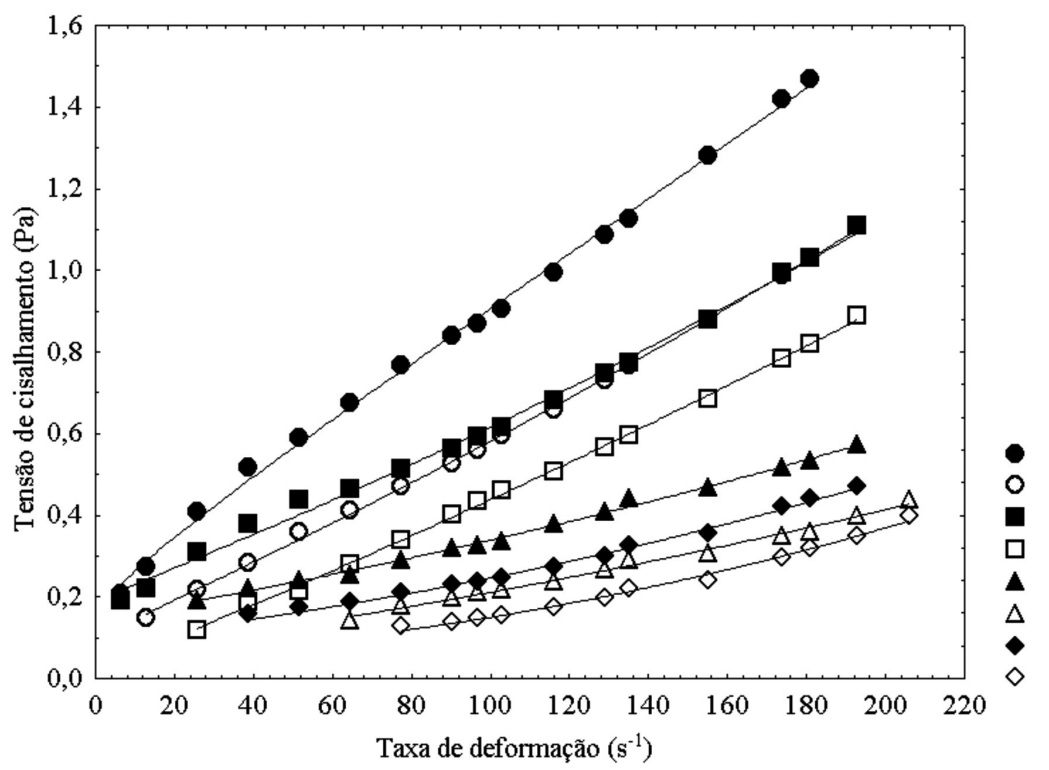

FIGURA 7- Relação entre tensão de cisalhamento e taxa de deformação das amostras $\mathrm{N}$ e D do suco de abacaxi ajustada pelo modelo de Mizrahi-Berk, nas quatro temperaturas utilizadas. 


\section{CONCLUSÕES}

1-Os resultados obtidos na otimização do tratamento enzimático do suco de abacaxi analisado mostram que a temperatura de $50{ }^{\circ} \mathrm{C}$ e o tempo de 80 minutos (ensaio 4) proporcionam redução de $94,03 \%$ no teor de pectina do mesmo.

2-O modelo de Mizrahi-Berk descreve de modo satisfatório o comportamento reológico das amostras analisadas, de acordo com os parâmetros avaliados.

3-Os sucos de abacaxi natural e despectinizado apresentam comportamento não-newtoniano com características de fluidos pseudoplásticos, possuindo valores de índice de comportamento (n) menores que a unidade.

4-Há redução dos valores de viscosidade aparente obtidos com o aumento da taxa de deformação, bem como da temperatura de análise.

5-A equação de Arrhenius representa de modo aceitável a dependência da viscosidade aparente das amostras em função da temperatura. A energia de ativação do suco aumentou de 4,54 Kcal.g.mol ${ }^{-1}$ para 4,89 Kcal.g.mol ${ }^{-1}$ com o tratamento enzimático.

6- O tratamento enzimático reduz a viscosidade aparente do suco de abacaxi em todas as temperaturas utilizadas.

\section{AGRADECIMENTOS}

Ao $\mathrm{CNPq}$, pelo apoio financeiro para a realização deste trabalho, e à Empresa Novozymes, pela concessão da enzima utilizada nos experimentos. Aos professores Dr. Rosinelson da Silva Pena e Dr. Hervé Louis Ghislain Rogez, pelo auxílio em determinadas etapas.

\section{REFERÊNCIAS}

ALKORTA, I.; GARBISU, C.; LLAMA, M.J.; SERRA, J.L. Industrial applications of pectic enzymes: a review. Process Biochemistry, Oxford, v.33, n.1, p.21-28, 1998.

ALPARSLAN, M.; HAYTA, M. Rheological and sensory properties of pekmez (grape molasses)/ tahin (sesame paste) blends. Journal of Food Engineering, Oxford, v.54, n.1, p.89-93, 2002.

BARROS, S.T.D.; MENDES, E.S.; PERES, L. Influence of depectinization in the ultrafiltration of west indian cherry (Malpighia glabra L.) and pineapple (Ananas comosus L.) juices. Ciência e Tecnologia de Alimentos, Campinas, v.24, n.2, p.194-201, 2004.
BHATTACHARYA, S. Yield stress and time-dependent rheological properties of mango pulp. Journal of Food Science, Chicago, v.64, n.6, p.1029-1033, 1999.

CONSTENLA, D.T.; LOZANO, J.E.; CRAPISTE, G.H. Thermophysical properties of clarified apple juice as a function of concentration and temperature. Journal of Food Science, Chicago, v.54, n.3, p.663-668, 1989.

FERREIRA, E.V.; BRANDÃO, P.R.G.; KLEIN, B.; PERES, A.E.C. Reologia de suspensões minerais: uma revisão. Revista Escola de Minas, Ouro Preto, v.58, n.1, p.83-87, 2005.

FERREIRA, G.M.; GUIMARÃES, M.J.O.C; MAIA, M.C.A. Efeito da temperatura e taxa de cisalhamento nas propriedades de escoamento da polpa de cupuaçu (T. grandiflorum Schum.) integral. Revista Brasileira de Fruticultura, Jaboticabal, v.30, n.2, p.385-389, 2008.

FERREIRA, G. M.; QUEIROZ, A. J. M.; CONCEIÇÃO, R. S.; GASPARETTO, C. A. Efeito da temperatura no comportamento reológico das polpas de cajú e goiaba. Revista Ciências Exatas e Naturais, Guarapuava, v.4, n.2, p.175-184, 2002.

GOMES, E.; GUEZ, M.A.U.; MARTIN, N.; SILVA, R. Enzimas termoestáveis: fontes, produção e aplicação industrial. Química Nova, São Paulo, v.30, n.1, p.136-145, 2006.

HASSAN, B.H.; HOBANI, A.I. Flow properties of Roselle (Hibiscus sabdariffa) extract. Journal of Food Engineering, Oxford, v.35, n.4, p.459-470, 1998.

JAYANI, R.S.; SAXENA, S.; GUPTA, R. Microbial pectinolytic enzymes: A review. Process Biochemistry, Oxford, v.40, p.2931-2944, 2005.

KHALIL, K.E., RAMAKRISHNA, P., NANJUNDASWAMY, A.M., PATWARDHAN, M.V. Rheological behaviour of clarified banana juice: effect of temperature and concentration. Journal of Food Engineering, Oxford, v.10, n.3, p.231-240,1989.

PELEGRINE, D.H.; VIDAL, J.R.M.B.; GASPARETTO, C.A. Estudo da viscosidade aparente das polpas de manga (Keitt) e abacaxi (Pérola). Ciência e Tecnologia de Alimentos, Campinas, v.20, n.1, p.128-131, 2000. 
PINHEIRO, A.M.; FERNANDES, A.G.; FAI, A. E.C.; PRADO, G.M.; SOUSA, P.H.M.; MAIA, G.A. Avaliação química, físico-química e microbiológica de sucos de frutas integrais: abacaxi, caju e maracujá. Ciência e Tecnologia de Alimentos, Campinas, v.26, n.1, p.98-103, 2006.

QUEIROZ, A.J.M.; VIDAL, J.R.M.B.; GASPARETTO, C.A. Influência de diferentes teores de sólidos insolúveis suspensos nas características reológicas de sucos de abacaxi naturais e despectinizados. Revista Brasileira de Engenharia Agrícola e Ambiental, Campina Grande, v.4, n.1, p.75-79, 2000.

SÁ, I.S.; CABRAL, L.M.C.; MATTA, V.M. Concentração de suco de abacaxi através dos processos com membranas. Brazilian Journal of Food Technology, Campinas, v.6, n.1, p.53-62, 2003.

SARZI, B.; DURIGAN, J.F. Avaliação física e química de produtos minimamente processados de abacaxi "pérola". Revista Brasileira de Fruticultura, Jaboticabal, v.24, n.2, p.333-337, 2002.
SILVA, F.C.; GUIMARÃES, D.H.P.; GASPARETTO, C.A. Reologia do suco de acerola: efeitos da concentração e temperatura. Ciência e Tecnologia de Alimentos, Campinas, v.25, n.1, p.121-126, 2005.

SOUTO, R.F., DURIGAN, J.F.; SOUZA, B.F.; DONADON, J.; MENEGUCCI, J.L.P. Conservação pós-colheita de abacaxi 'Pérola' colhido no estádio de maturação "pintado", associando-se refrigeração e atmosfera modificada. Revista Brasileira de Fruticultura, Jaboticabal, v.26, n.1, p.24-28, 2004.

TORALLES, R.P.; VENDRUSCOLO, J.L.; VENDRUSCOLO, C.T. Reologia do purê Homogeneizado de pêssego: Efeito da temperatura e concentração. Brazilian Journal of Food Technology, Campinas, v.9, n.1, p.1-8, 2006.

VAILLANT, F.; MILLAN, A.; DORNIER, M.; DECLOUX, M.; REYNES, M. Strategy for economical optimization of the clarification of pulpy fruit juices using crossflow microfiltration. Journal of Food Engineering, Oxford, v.48, p.83-90, 2001. 